\title{
4. Ergebnisse der einzelnen Projekte
}

\author{
K. von Berlepsch
}

Die Übersichten über die 15 im Programm ausgeführten Projekte wurden von der Programmleitung und von der Expertengruppe des NFP34 redigiert und decken sich nicht zwangsläufig mit Ansichten des jeweiligen Projektleiters. Durch das Beibehalten eines möglichst konsistenten Stils soll die Lektüre erleichtert werden. Diese Übersicht basiert weitgehend auf den Schlussberichten der einzelnen Projektleiter, enthält allerdings noch zusätzliche, projektübergreifende Bemerkungen der Programmleitung. Damit sollen z.B. konzeptionelle oder methodische Gemeinsamkeiten oder Probleme in den einzelnen Projekten angedeutet werden. Die Arbeiten wurden folgenden drei Unterkapiteln zugeordnet:
Sozioökonomische Aspekte
4.1. J. Sommer
Gesundheitsökonomische
Analyse
4.2. A. Schär,
V. Messerli-Rohrbach
4.3. M. Künzi
4.4. O. Guillod
Gesundheitsrecht Schweiz
Gesundheitsrecht Europa

Klinische Aspekte

4.5. I B. Hochstrasser, Schwangerschaftsbegleitung

P. Mattmann (Homöopathie/Schulmedizin)

4.5. II B. Hochstrasser Lebensqualität bei Schwangeren

4.6. T. Medici Bronchialasthma (Akupunktur)

4.7. H. Montakab Schlafstörungen (Akupunktur)

4.8. B. Suter Grundlagenarbeit zur

Akupunktur (Mikrozirkulation)

4.9. T. Cerny

P. Heusser

4.10. A. Kesselring

4.11. E. Buchser

Lebensqualität bei Krebs

(anthroposophisch erweitertes

Heilwesen)

Akutschmerzen nach Operation

(Fussreflexzonen-Massage)

Chronische Schmerzen

(Hypnose)

\subsection{T. Gysin}

4.13. A. Bircher
4.14. A. Wille

Spannungskopfschmerzen bei Jugendlichen (Hypnose)

Selbsthypnose bei Pollinosis

Stottern bei Kindern

(Bioresonanz)

Physiologische Aspekte

4.15. V. von Tscharner

Elektromyographie und Radiästhesie (Grundlagenarbeit)

Im nachfolgenden Kapitel 5 (siehe S. 56) dieses Schlussberichts kommen die Schlussfolgerungen, die seitens der Programmleitung gezogen werden konnten, zur Sprache.

\begin{tabular}{ll}
\hline KARGER & $\oplus 1999$ S. Karger GmbH, Freiburg \\
$\begin{array}{l}\text { Fax (07 61) 4520714 } \\
\begin{array}{l}\text { E-mail kargergmbh@aol.com } \\
\text { www.karger.com }\end{array}\end{array}$ & Accessible online at: \\
http://BioMedNet.com/karger
\end{tabular}

Dr. med. Klaus von Berlepsch Hackbergstrasse 37

CH-4125 Riehen (Schweiz) 